\title{
Analysis of Changes in Precipitation and Drought in Aksu River Basin, Northwest China
}

\author{
Yuhu Zhang, ${ }^{1}$ Wanyuan Cai, ${ }^{1}$ Qiuhua Chen, ${ }^{2}$ Yunjun Yao, ${ }^{3}$ and Kaili Liu ${ }^{2}$ \\ ${ }^{1}$ College of Resources Environment \& Tourism, Capital Normal University, Beijing 100048, China \\ ${ }^{2}$ School of Mathematical Sciences, Capital Normal University, Beijing 100048, China \\ ${ }^{3}$ State Key Laboratory of Remote Sensing Science, College of Global Change and Earth System Science, \\ Beijing Normal University, Beijing 100875, China \\ Correspondence should be addressed to Wanyuan Cai; 743483324@qq.com
}

Received 23 October 2014; Revised 15 January 2015; Accepted 11 February 2015

Academic Editor: Ming Pan

Copyright ( $\odot 2015$ Yuhu Zhang et al. This is an open access article distributed under the Creative Commons Attribution License, which permits unrestricted use, distribution, and reproduction in any medium, provided the original work is properly cited.

\begin{abstract}
The analysis of the spatiotemporal trends of precipitation and drought is relevant for the future development and sustainable management of water resources in a given region. In this study, precipitation and Standardized Precipitation Index (SPI) trends were analyzed through applying linear regression, Mann-Kendall, and Spearman's Rho tests at the 5\% significance level. For this goal, meteorological data from 9 meteorological stations in and around Aksu Basin during the period 1960-2010 was used, and two main annual drought periods were detected (1978-1979 and 1983-1986), while the extremely dry years were recorded in 1975 and 1985 at almost all of the stations. The monthly analysis of precipitation series indicates that all stations had increasing trend in July, October, and December, while both increasing and decreasing trends were found in other months. For the seasonal scale, precipitation series had increasing trends in summer and winter. 33\% of the stations had the decreasing trend on precipitation in the spring series, and it was $11 \%$ in the autumn. At the same time, the SPI- 12 values of all stations had the increasing trend. The significant trends were detected at Aheqi, Baicheng, Keping, and Kuche stations.
\end{abstract}

\section{Introduction}

Drought is the result of insufficient or lack of rainfall for an extended period, which causes a substantial hydrological (water) imbalance. Numerous indices have been applied to determine different drought characteristics depending on the study purpose. Precipitation-based drought indices with prearranged thresholds are valid since the main reason of drought is rainfall deficit $[1,2]$.

In the past decade, many scientists have analyzed the spatial variability of drought using drought indices and precipitation characteristics [2-8]. There were a lot of studies on drought [8-13] and various indices have been applied to measure different drought characteristics depending on research goals. The study related to precipitation is a prerequisite for other research studies. Analysis of precipitation data outputs helpful conclusion, which will be applied to plan and manage water resources system. For arid and semiarid regions, precipitation is a particularly important factor for water resources planning and drought risk management. Moreover, arid areas propose a challenge due to large contradistinction between dry and wet conditions within a temporal cycle.

The arid region of northwest China is one of the most sensitive areas in the world in terms of responding to global climate change $[14,15]$. The Aksu River Basin is located in the western part of the middle southern slope of the Tianshan Mountains and at the northwestern edge of the Tarim Basin in Xinjiang Uygur Autonomous Region of northwestern China. Research on drought for this area can contribute to early warning and water resource plan. Therefore, it is important to research the spatiotemporal trend of precipitation and drought in the past several decades in the Aksu River Basin.

Many scholars have studied the characteristics of precipitation changes in different regions in China over the past 50 years $[16-20]$. The major results indicated that precipitation in summer in eastern China shifted southward in the late 1970s [21, 22], national average precipitation increased with 
the increasing precipitation in spring but slightly decreasing in autumn in the last decades [23] and the frequency of heavy precipitation events increased in China [24]. Mechanisms have also been proposed to explain precipitation changes [2527]. Affected by decadal changes of the global climate system, precipitation in China is characterized with significant decadal changes, especially since the 1990s, and the increased global warming plus the reenhanced East Asian monsoon are bound to influence the regional precipitation distribution and its changing trend. Precipitation changes might greatly affect regional climate stability, hydrological processes, and water availability.

Furthermore, there have been a number of drought and precipitation studies for different periods in Aksu River Basin. Related studies [28-35] have indicated that there is a change about precipitation and drought indices. For example, Chen et al. [36] summarized that the streamflow from the headwaters of the Tarim River shows significant increase and is sensitive to precipitation, but the streamflow along the mainstream of the river has decreased. Chen et al. [37, 38] analyzed the fifty-year climate change and its effect on annual runoff at Aksu River Basin. The streamflow showed a significant increasing monotonic trend. The annual runoff in the Aksu River had increased by $10.9 \%$ since 1990 . They also detected the long-term trends of the hydrological time series using both parametric and nonparametric techniques based on temperature and precipitation data from the past 50 years. The temperature, the precipitation, and the streamflow from the headwater of the Tarim River exhibited a significant increase during the last 20 years. Lee and Zhang [39] further developed the relationship between $\mathrm{NAO}$ and drought disasters in northwestern China. Statistical results show that NAO and drought disaster were negatively correlated, as positive modes of NAO caused northwarddisplaced, stronger-than-average midlatitude Westerlies with an enhanced latitudinal water vapor gradient into the central Asian drylands, resulting in reduced drought frequency and intensity in northwestern China. Ling et al. [40] investigated intra-annual runoff trends and periods in the headstream areas of the Tarim River Basin by nonparametric tests and wavelet analysis. The results showed that the runoff, air temperature, and precipitation of the headstreams increased remarkably during both high-flow and low-flow periods.

However, most of the previous work on a comprehensive analysis of trends and variability using statistical test and drought indices in precipitation series over Aksu River Basin is still lacking. Thus, it is necessary to analyze the trend of precipitation and characteristics of drought to explore the causes and the formation mechanism of Aksu River Basin drought, which is vital for drought forecast, defense, and mitigation. The analysis of drought variability can improve water resources management in the area.

The main goals of the study were to study variability of precipitation on monthly, seasonal, and annual time scale through applying the linear regression, Mann-Kendall, and Spearman's Rho methods to assess precipitation prediction for the Aksu River Basin in China and to analyze the impact of serial correlation in detecting trends and to investigate the drought in study area from 1960 to 2010.

\section{Materials and Methods}

2.1. Study Area and Database. The Aksu River Basin $\left(75^{\circ} 35-\right.$ $\left.82^{\circ} 00^{\prime} \mathrm{E} ; 40^{\circ} 17-42^{\circ} 27^{\prime} \mathrm{N}\right)$ is located in the western part of the middle southern slope of the Tianshan Mountains and at the northwestern edge of the Tarim Basin. The total area is $5.14 \times 10^{4} \mathrm{~km}^{2}$, of which the area of the region in China is $3.1 \times 10^{4} \mathrm{~km}^{2}$. The basin is in the interior of the Eurasian continent. Vast territory, diverse topography, complex terrain, and typical regional climate variations made up the characteristics of the northwest mountain climate. It has lower temperatures, plentiful precipitation, and aged snow in the high mountain zone, while the middle mountain zone brings about changes in temperature clearly and is the largest precipitation distribution area. The low mountain zone suffers from drought, large temperature changes, and is fairly well in heat conditions. Due to the Taklimakan Desert in the south and the Tianshan Mountains in the north, the cool air and vapor derived from Central Asia, Siberia, and Arctic Ocean do not straightly enter into the southeastern plain region, which causes typical temperate continental dry climate regional characteristics such as minimal precipitation, intense evaporation, adequate sunshine, and extreme heat [41].

Daily precipitation, saturation vapor pressure, net radiation, soil heat flux density, temperature, average $24 \mathrm{~h}$ wind speed at $2 \mathrm{~m}$ height, and vapor pressure data were collected from 9 meteorological stations distributed in study area (shown in Figure 1) for the period 1961-2010 and were obtained from meteorological data shared in service system of China (http://data.cma.gov.cn/). Seasons were defined as follows: winter $=$ December, January, and February; spring = March, April, and May; summer = June, July, and August, and autumn = September, October, and November. The geographical location of the selected meteorological stations is presented in Table 1.

The precipitation datasets were investigated for homogeneity and absence of trends. The autocorrelation analysis was applied to the monthly precipitation time series of each station. The precipitation data were quality controlled (QC) from [42].

2.2. Rainfall Variability Index (RVI). RVI $(\delta)$ is calculated as follows:

$$
\delta_{i}=\frac{\left(P_{i}-\mu\right)}{\sigma},
$$

where $\delta_{i}=$ Rainfall Variability Index for year $i, P_{i}=$ annual rainfall for year $i$, and $\mu$ and $\sigma$ are the mean annual rainfall and standard deviation for the period of the year 1961-2010. A drought year occurs if the $\delta$ is negative.

According to WMO [43], rainfall time series can be classified into different climatic regimes:

$$
\begin{gathered}
\text { extreme dry: } P<\mu-2 \cdot \sigma, \\
\text { dry: } \mu-2 \cdot \sigma<P<\mu-\sigma, \\
\text { normal: } \mu-\sigma<P<\mu+\sigma, \\
\text { wet: } P>\mu+\sigma .
\end{gathered}
$$




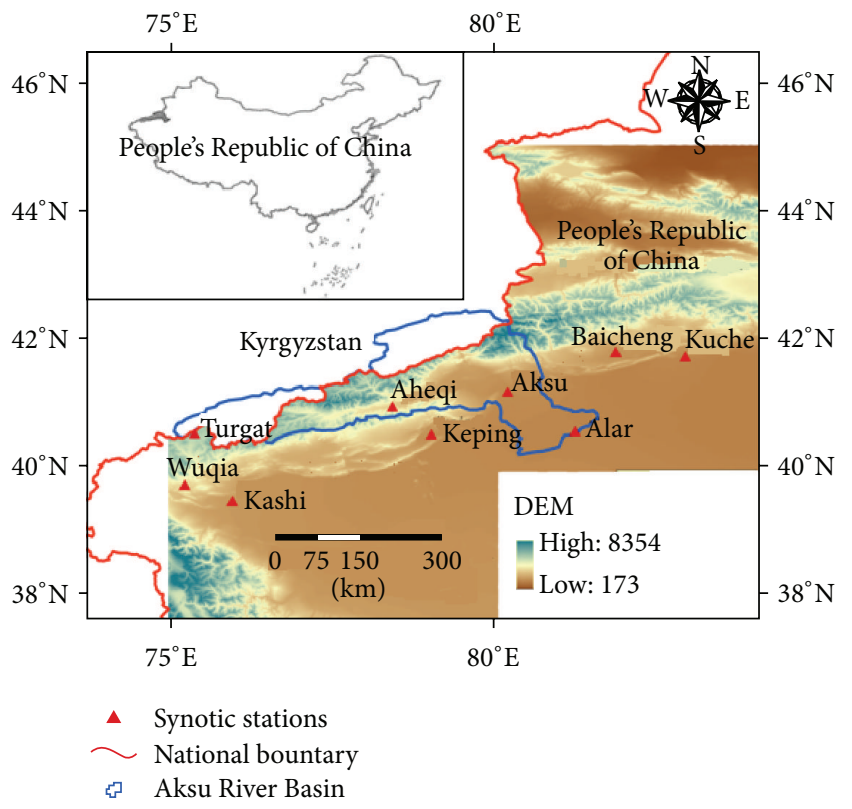

Figure 1: Location map of the 9 synoptic stations in Aksu River Basin of China.

TABLE 1: Location of the stations.

\begin{tabular}{lcccc}
\hline Site name & Code & Lat. $(\mathrm{N})$ & Long $(\mathrm{E})$ & Elev. $(\mathrm{m})$ \\
\hline Aksu & 51628 & 41.10 & 80.14 & 1105 \\
Aheqi & 51711 & 40.93 & 78.45 & 1986 \\
Alar & 51730 & 40.55 & 81.27 & 1012 \\
Baichen & 51633 & 41.79 & 81.9 & 1229 \\
Keping & 51720 & 40.5 & 79.05 & 1162 \\
Kuche & 51644 & 41.72 & 82.97 & 1082 \\
Turgat & 51701 & 40.31 & 75.24 & 3507 \\
Wuqia & 51705 & 39.72 & 75.25 & 2176 \\
Kashi & 51709 & 39.28 & 75.59 & 1291 \\
\hline
\end{tabular}

2.3. Aridity Index (AI). In this study, we employed Aridity Index [44] to quantify the drought occurrence as a numerical indicator of the degree of dryness of the climate at each study location. According to the ratio of precipitation $(P)$ to potential evapotranspiration (PET), regions were classified from extremely arid to humid. PET was calculated using the FAO Penman-Monteith method widely [45]. It can be calculated as [46]

$$
\mathrm{PET}=\frac{0.408 \cdot \Delta \cdot\left(R_{n}-G\right)+\gamma \cdot(900 /(T+273)) U_{2} \cdot \mathrm{VPD}}{\Delta+\gamma \cdot\left(1+0.34 \cdot U_{2}\right)},
$$

where PET $=$ potential evapotranspiration $\left(\mathrm{mm} \mathrm{day}^{-1}\right) ; \Delta=$ slope of the saturation vapor pressure function $\left(\mathrm{kPa}^{\circ} \mathrm{C}^{-1}\right)$; $R_{n}=$ net radiation $\left(\mathrm{MJ} \mathrm{m}^{-2}\right.$ day $\left.^{-1}\right) ; G=$ soil heat flux density $\left(\mathrm{MJ} \mathrm{m}{ }^{-2}\right.$ day $\left.^{-1}\right) ; \gamma=$ psychometric constant $\left(\mathrm{kPa}^{\circ} \mathrm{C}^{-1}\right) ; T=$ mean air temperature $\left({ }^{\circ} \mathrm{C}\right) ; U_{2}=$ average 24 -h wind speed at $2 \mathrm{~m}$ height $\left(\mathrm{ms}^{-1}\right)$; and VPD = vapor pressure deficit $(\mathrm{kPa})$.

The locations were then classified as extremely arid $(P /$ PET $\leq 0.05)$, arid $(0.05<P /$ PET $\leq 0.2)$, semiarid $(0.2<P /$ PET $\leq 0.5)$, subhumid $(0.5<P /$ PET $\leq 0.65)$, or humid $(P /$ PET $>0.65)[2,47]$.

2.4. Drought Indices. Drought indices are the most indispensable elements for drought analysis and monitoring since they enable identification and quantification of droughts. There have been numerous drought indices such as Standardized Precipitation Index (SPI), the Palmer Hydrological Drought Index (PHDI), Standardized Precipitation Evapotranspiration Index (SPEI), the Surface Water Supply Index (SWSI), Palmer Drought Severity Index (PDSI), and the Standardized Anomaly Index (SAI). The establishment of unique and universally accepted drought indices does not exist, although a number of drought indices have been proposed [13, 48, 49].

In this study, the SPI was applied, because of its good characteristics in drought identification and prediction of drought class transitions [8-10]. During the first decade of the 21st century, the Standardized Precipitation Index (SPI) was widely used. And it is simple and considers only precipitation data, which can be found nearly everywhere.

2.4.1. Standardized Precipitation Index. The Standardized Precipitation Index (SPI) was proposed by McKee et al. [50, 51] to indicate the precipitation deficit at different time scales (i.e., accumulated over given time spans). The SPI is a probability index that involves only precipitation. The probabilities are standardized so that an index of zero indicates the mean precipitation amount. The relative simplicity of the SPI is one solid advantage of the index [52]. The main criticism to the SPI is that its calculation is based solely on precipitation data, not considering other variables that determine drought conditions such as temperature, evapotranspiration, wind speed, or the soil water holding capacity.

Calculating the SPI for a certain time period at any places requires completed monthly data for the quantity of precipitation, at least 30 -annual sequence $[53,54]$.

SPI is mathematically based on the cumulative probability of some precipitation recorded at the observation post. Research has shown that precipitation is subject to the law of gamma distribution [55-57]. One whole period of observation at one meteorological station is used to determine the parameters of scaling and the forms of precipitation probability density function:

$$
g(x)=\frac{1}{\beta^{\alpha} \cdot \Gamma(\alpha)} x^{\alpha-1} \cdot e^{-x / \beta}, \quad x>0,
$$

where $\alpha=$ form parameter; $\beta=$ scale parameter; $x=$ precipitation quantity; $\Gamma(\alpha)=$ gamma function defined by the following statement:

$$
\Gamma(\alpha)=\int_{0}^{\infty} y^{\alpha-1} e^{-y} d y .
$$


Parameters $\alpha$ and $\beta$ are determined by the method of maximum probability for a multiyear data sequence; that is,

$$
\begin{gathered}
\alpha_{\text {pro }}=\frac{1}{4 A}\left(1+\sqrt{1+\frac{4 A}{3}}\right), \\
A=\ln \left(x_{\mathrm{sr}}\right)-\frac{\sum_{i=1}^{n} \ln \left(x_{i}\right)}{n}, \\
\beta_{\text {pro }}=\frac{x_{\mathrm{sr}}}{\alpha_{\text {pro }}}
\end{gathered}
$$

where $x_{\text {sr }}$ is the mean value of precipitation quantity; $n$ is the precipitation measurement number; $x_{i}$ is the quantity of precipitation in a sequence of data.

The acquired parameters are further applied to the determination of a cumulative probability of certain precipitation for a specific time period in a time scale of all the recorded precipitation. The cumulative probability can be presented as

$$
G(x)=\int_{0}^{x} g(x) d x=\frac{1}{\beta_{\text {pro }}^{x_{\text {pro }}} \Gamma\left(\alpha_{\text {pro }}\right)} \int_{0}^{x} x^{\alpha_{\text {pro }}-1} e^{-x / \beta_{\text {pro }}} d x .
$$

Because the gamma function has not been defined for $x=$ 0 and the precipitation may be up to zero, the cumulative probability becomes

$$
H(x)=q+(1-q) G(x),
$$

where $q$ is the probability that the quantity of precipitation equals zero, which is calculated using the following equation:

$$
q=\frac{m}{n}
$$

where $m$ is the number which represented how many times the precipitation was zero in a temporal sequence of data and $n$ is the precipitation observation number in a sequence of data.

The calculation of the SPI is presented on the basis of the following equation [58-60]:

$$
\mathrm{SPI}= \begin{cases}-\left(t-\frac{c_{0}+c_{1} t+c_{2} t^{2}}{1+d_{1} t+d_{2} t^{2}+d_{3} t^{3}}\right), & 0<H(x) \leq 0.5, \\ +\left(t-\frac{c_{0}+c_{1} t+c_{2} t^{2}}{1+d_{1} t+d_{2} t^{2}+d_{3} t^{3}}\right), & 0.5<H(x) \leq 1.0,\end{cases}
$$

where $t$ is determined as

$$
t= \begin{cases}\sqrt{\frac{\ln \frac{1}{(H(x))^{2}}}{(1-H(x))^{2}}}, & 0<H(x) \leq 0.5, \\ \sqrt{\ln \frac{1}{(1-x) \leq 1.0}} .\end{cases}
$$

And $c_{0}, c_{1}, c_{2}, d_{1}, d_{2}$, and $d_{3}$ are coefficients whose values are $[58-60]$

$$
\begin{array}{lll}
c_{0}=2.515517, & c_{1}=0.802853, & c_{2}=0.010328, \\
d_{1}=1.432788, & d_{2}=0.189269, & d_{3}=0.001308 .
\end{array}
$$

TABLE 2: Drought classification of SPI.

\begin{tabular}{lc}
\hline Drought class & SPI value \\
\hline Nondrought & SPI $\geq 0$ \\
Near normal & $-1<$ SPI $<0$ \\
Moderate & $-1.5<$ SPI $\leq-1$ \\
Severe/extreme & SPI $\leq-1.5$ \\
\hline
\end{tabular}

The drought classification of SPI is presented in Table 2 that grouped the severe and extremely severe drought classes for modeling aims since transitions referring to the extremely severe droughts are much less frequent than those for other classes [9]. The SPI on shorter time scales (e.g., 3 and 6 months) describes drought events affecting agricultural practices. In this study, the SPI at 12-month time scale was selected and analyzed because it is more suitable for water resources management purposes in a certain region and more appropriate for identifying the persistence of dry periods $[8,10,13,61,62]$.

According to the criteria of McKee et al. [50, 51], severe and extreme droughts corresponding to the categories, respectively, are as shown in Table 2.

2.5. Statistical Methods. Many statistical techniques (parametric or nonparametric) have been developed to detect trends within time series such as linear regression, Spearman's Rho test, Mann-Kendall test, Sen's slope estimator, and Bayesian procedure [63-68]. In this study, the MannKendall and Spearman's Rho tests were used to analyze the precipitation trends, while the linear regression was used to calculate magnitude of trends.

2.5.1. Mann-Kendall Trend Test. The Mann-Kendall test statistic $S[69,70]$ is calculated as

$$
S=\sum_{i=1}^{n-1} \sum_{j=i+1}^{n} \operatorname{sgn}\left(x_{j}-x_{i}\right)
$$

where $n$ is the number of data points, $x_{i}$ and $x_{j}$ are the data values in time series $i$ and $j(j>i)$, respectively, and $\operatorname{sgn}\left(x_{j}-\right.$ $x_{i}$ ) is the sign function determined as

$$
\operatorname{sgn}\left(x_{j}-x_{i}\right)= \begin{cases}+1, & \text { if } x_{j}-x_{i}>0 \\ 0, & \text { if } x_{j}-x_{i}=0 \\ -1, & \text { if } x_{j}-x_{i}<0\end{cases}
$$

In cases where the sample size $n>10$, the mean and variance are given by

$$
\begin{gathered}
\mu(S)=0, \\
\sigma^{2}(S)=\frac{n(n-1)(2 n+5)-\sum_{i=1}^{m} t_{i}\left(t_{i}-1\right)\left(2 t_{i}+5\right)}{18},
\end{gathered}
$$

where $m$ is the number of tied groups and $t_{i}$ denotes the number of ties of extent $i$. A tied group is a set of sample data having the same value. 
In the absence of ties between the observations, the variance is computed as

$$
\sigma^{2}(S)=\frac{n(n-1)(2 n+5)}{18} .
$$

The standard normal test statistic $Z_{S}$ is computed as

$$
Z_{S}= \begin{cases}\frac{S-1}{\sqrt{\sigma^{2}(S)},} & \text { if } S>0, \\ 0, & \text { if } S=0, \\ \frac{S+1}{\sqrt{\sigma^{2}(S)}}, & \text { if } S<0 .\end{cases}
$$

Positive values of $Z_{S}$ indicate increasing trends while the negative $Z_{S}$ shows decreasing trends.

Testing of trends is done at a specific $\alpha$ significance level. In this study, the significance level of $\alpha=0.05$ was used. At the $5 \%$ significance level, the null hypothesis of no trend is rejected if $\left|Z_{S}\right|>1.96$.

2.5.2. Spearman's Rho Test. Spearman's Rho test is nonparametric method commonly used to verify the absence of trends. Its statistic $D$ and the standardized test statistic $Z_{D}$ are expressed as follows $[71,72]$ :

$$
\begin{gathered}
D=1-\frac{6 \sum_{i=1}^{n}\left(R\left(X_{i}\right)-i\right)^{2}}{n\left(n^{2}-1\right)}, \\
Z_{D}=D \sqrt{\frac{n-2}{1-D^{2}}},
\end{gathered}
$$

where $R\left(X_{i}\right)$ is the rank of $i$ th observation $X_{j}$ in the time series and $n$ is the length of the time series.

Positive values of $Z_{D}$ indicate increasing trends while negative $Z_{D}$ show decreasing trends. At the $5 \%$ significance level, the null hypothesis of no trend is rejected if $\left|Z_{D}\right|>2.08$.

2.5.3. Serial Autocorrelation Test. To remove serial correlation from the series, von Storch and Navarra [73] suggested to prewhiten the series before applying the Mann-Kendall and Spearman's Rho tests. The lag-1 serial correlation coefficient of sample data $x_{i}$ (designated by $r_{1}$ ) is computed as $[74,75]$

$$
\begin{gathered}
r_{1}=\frac{(1 /(n-1)) \sum_{i=1}^{n-1}\left(x_{i}-\mu\left(x_{i}\right)\right) \cdot\left(x_{i+1}-\mu\left(x_{i}\right)\right)}{(1 / n) \sum_{i=1}^{n}\left(x_{i}-\mu\left(x_{i}\right)\right)^{2}} \\
\mu\left(x_{i}\right)=\frac{1}{n} \sum_{i=1}^{n} x_{i},
\end{gathered}
$$

where $\mu\left(x_{i}\right)$ is the mean of sample data and $n$ is the sample size.

For the two-sided test, Unkašević and Tošić [68] recommended that the 0.05 significance level for $r_{1}$ can be computed by

$$
r_{1}(0.05)=\frac{-1 \pm 1.96 \sqrt{n-2}}{n-1}
$$

where $n$ is the sample size.

\section{Results and Discussion}

3.1. Summary of Statistical Parameters. Statistical parameters of monthly precipitation time series at 9 synoptic stations during the period 1960-2010 are summarized in Table 3. The minimal monthly precipitation is $0 \mathrm{~mm}$ for all stations. The mean monthly precipitation is ranged from $4.076 \mathrm{~mm}$ to $20.554 \mathrm{~mm}$. Moreover, it is obvious that 3 mountainous synoptic stations in the northwest (Aheqi, Turgat, and Wuqia) had the highest mean monthly precipitation.

The highest kurtosis of the precipitation values was observed at Aksu station with 16.699, while the lowest kurtosis of 2.682 was found at Turgat. This phenomenon indicated that the monthly precipitation in Turgat is relatively homogeneous. But it is converse in Aksu.

Time series of annual precipitation at the 9 synoptic stations are shown in Figure 2. The results indicated that the annual precipitation had a certain degree of variance during the observed period. In Aksu, Alar, Kuche, and Kashi, the annual precipitation is relatively low and basic by about $50 \mathrm{~mm}$. However, the annual precipitation in Aheqi, Wuqia, and Turgat, is above $200 \mathrm{~mm}$. In addition, the annual precipitation in Baicheng, Kuche, and Keping has obvious upward trend during the observed period. These results show that the precipitation in upstream of Aksu basin is larger than that in downstream.

3.2. Aridity Index. The estimated UNEP Aridity Index for the 9 synoptic stations is given in Table 4. The FAO-56 PenmanMonteith equation as a part of the model based on serviceoriented paradigm $[76,77]$ is used for estimating PET. The results indicated that the Aridity Index ranged from 0.048 at the Alar station to 0.397 at the Turgat station. The Alar station is extremely arid and the Aheqi station and the Turgat station are semiarid, while all other stations are arid. The upper limit for extremely arid climate is 0.05 , but Alar had a slightly lower value. The Alar station is extremely arid because of the highest PET, minimum of the annual precipitation, and the highest value of the temperature difference.

3.3. Rainfall Variability. Annual rainfall variability indices for the observed synoptic stations are shown in Figure 3, while the percentage distribution of dry, normal, and wet years during the period 1960-2010 is given in Figure 4. It is obvious that there was no extremely dry year for all stations. Although, considering both time series of precipitation and annual rainfall variability indices for the 9 synoptic stations, there were two main periods which were characterized by long and severe droughts, namely, 1978-1979 and 1983-1986.

During the first period, the drought years were approximately $55 \%$ of the total years. The second period is characterized by approximately $47 \%$ of the drought years. In addition, it should be noticed that there were 4 dry years, $1961,1975,1985$, and 2007. These four years were characterized by approximately $89 \%$ negative values of the annual rainfall variability index.

3.4. Analysis of Precipitation. The serial correlation coefficient can improve the verification of the independence of 
TABLE 3: Statistical parameters of monthly precipitation time series at 9 synoptic stations during the period 1960-2010.

\begin{tabular}{lccccccc}
\hline Station name & Min $(\mathrm{mm})$ & Max $(\mathrm{mm})$ & Mean $(\mathrm{mm})$ & Standard deviation $(\mathrm{mm})$ & CV $(\%)$ & Skewness & Kurtosis \\
\hline Aksu & 0 & 92.2 & 6.162 & 10.148 & 164.672 & 3.343 \\
Aheqi & 0 & 145.2 & 17.920 & 23.597 & 131.676 & 1.983 & 4.520 \\
Alar & 0 & 50.9 & 4.076 & 7.546 & 185.139 & 2.737 \\
Baicheng & 0 & 76.8 & 9.920 & 12.367 & 124.664 & 2.115 & 5.473 \\
Keping & 0 & 81.2 & 8.029 & 13.348 & 166.253 & 2.553 \\
Kuche & 0 & 65.3 & 5.818 & 8.832 & 151.812 & 2.499 & 7.537 \\
Turgat & 0 & 122.1 & 20.554 & 21.380 & 104.015 & 1.615 \\
Wuqia & 0 & 121.6 & 15.009 & 18.471 & 123.071 & 1.878 \\
Kashi & 0 & 78.5 & 5.615 & 9.561 & 170.283 & 3.099 \\
\hline
\end{tabular}

Note: cv-coefficient of variation.

TABLE 4: Aridity Index, annual precipitation, and reference evapotranspiration estimated using FAO-56 Penman-Monteith equation.

\begin{tabular}{|c|c|c|c|c|}
\hline Station name & Precipitation (mm/year) & PET (mm/year) & Aridity index & Climate \\
\hline Aksu & 73.947 & 972.22 & 0.076 & Arid \\
\hline Aheqi & 215.045 & 985.51 & 0.218 & Semiarid \\
\hline Alar & 48.910 & 1023.91 & 0.048 & Extreme arid \\
\hline Baicheng & 119.041 & 832.52 & 0.143 & Arid \\
\hline Keping & 96.343 & 1102.73 & 0.087 & Arid \\
\hline Kuche & 69.812 & 1164.73 & 0.060 & Arid \\
\hline Turgat & 246.653 & 621.34 & 0.397 & Semiarid \\
\hline Wuqia & 180.106 & 1082.91 & 0.166 & Arid \\
\hline Kashi & 67.380 & 1125.91 & 0.060 & Arid \\
\hline
\end{tabular}
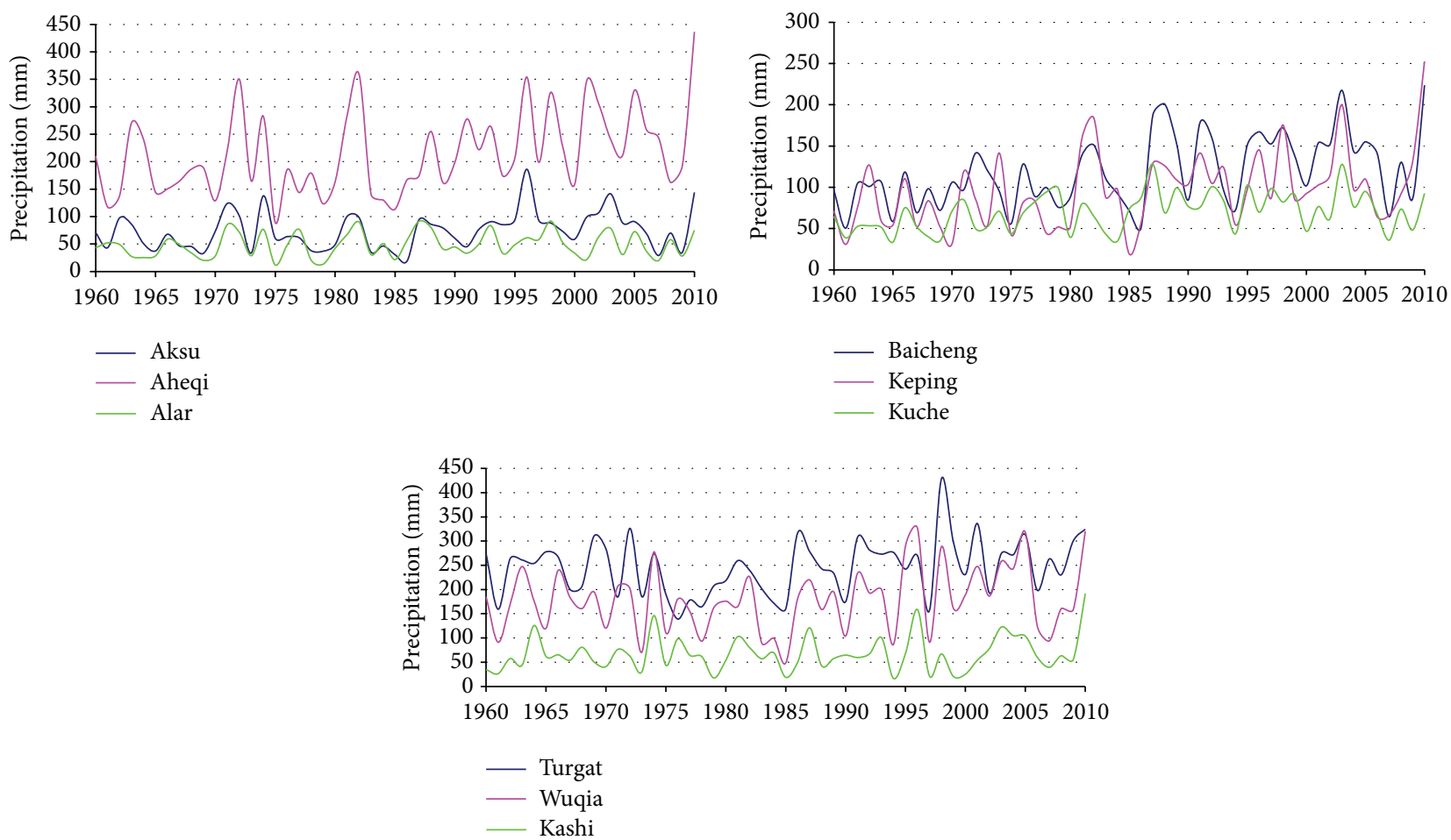

FIGURE 2: Annual precipitation time series at the 9 synoptic stations. 

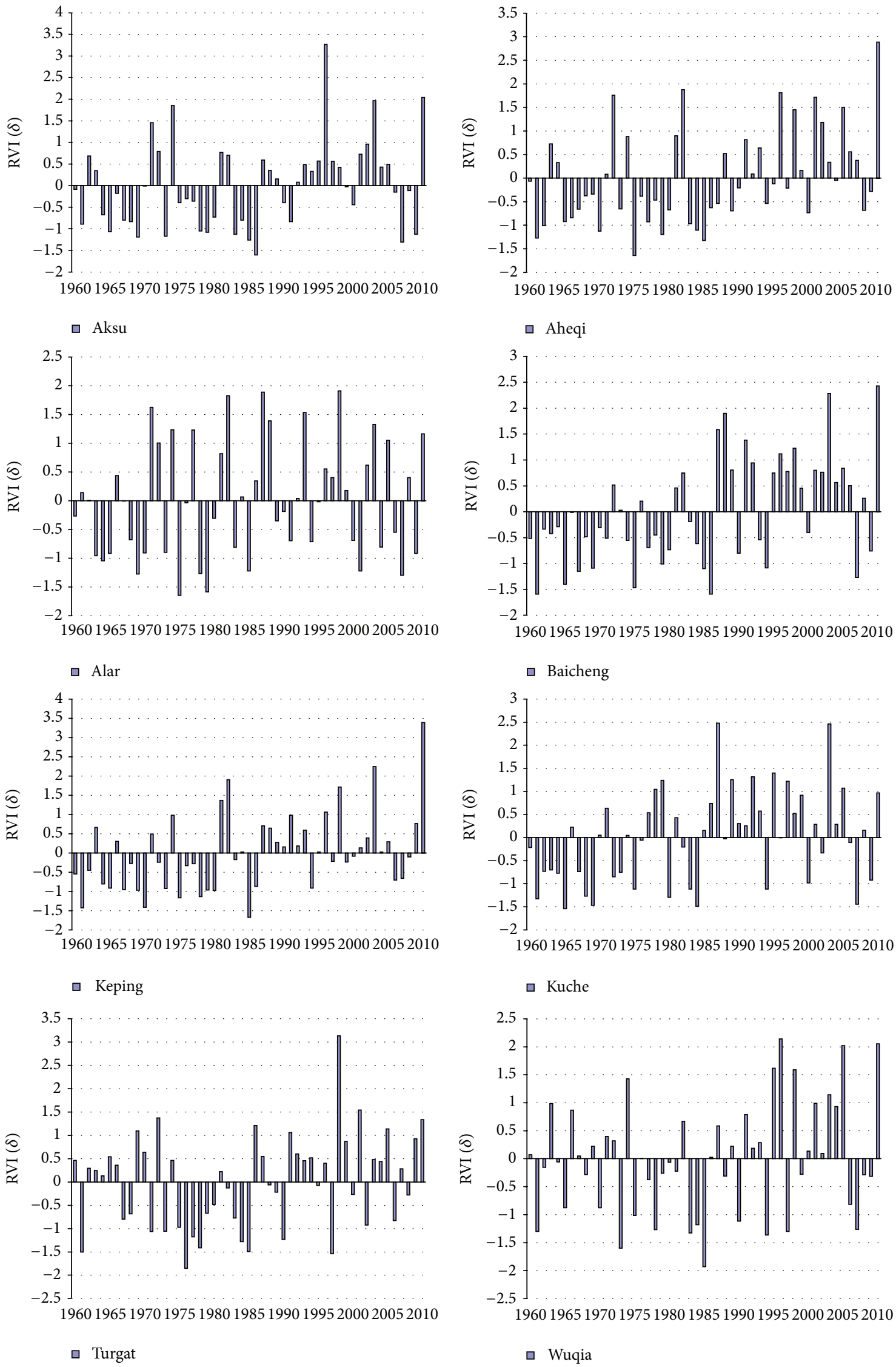

Figure 3: Continued. 


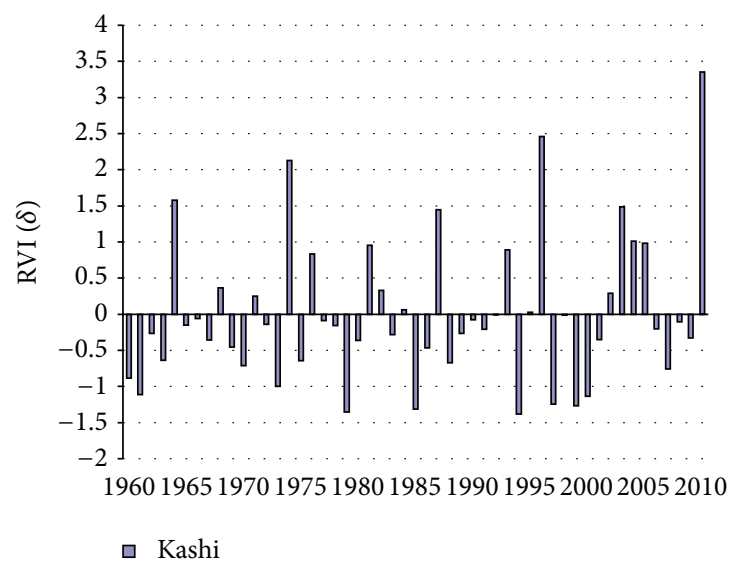

FIgURE 3: Annual rainfall variability indices for the 9 synoptic stations.

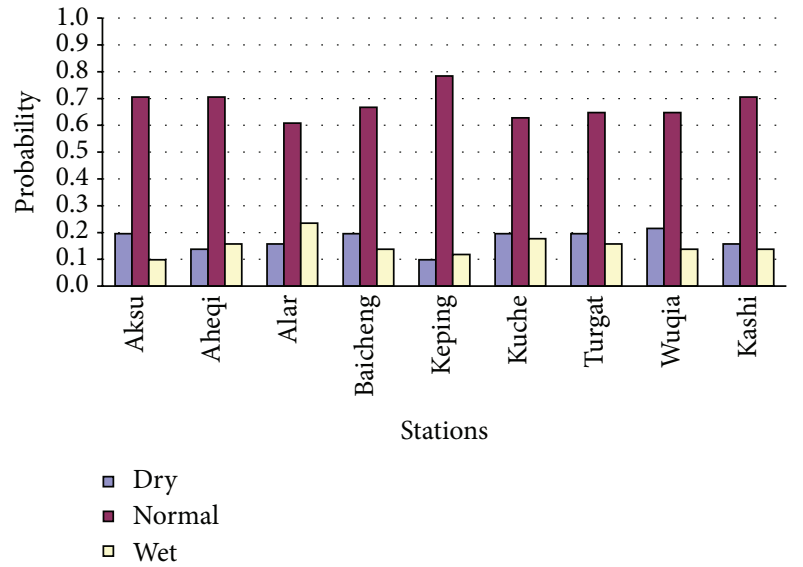

FIGURE 4: Distribution in percentage of dry, normal, and wet years for the 9 synoptic stations during the period 1960-2010.

precipitation time series. If the time series are completely random, the autocorrelation function will be zero for all lags other than zero. In this study, to accept the hypothesis $H_{0}$ : $r_{1}=0$ (that there is no correlation between two consecutive observations and there is no persistence in the time series), the value of $r_{1}$ should fall between -0.2544 and 0.2544 .

Autocorrelation plot for the annual precipitation at the 9 synoptic stations is presented in Figure 5. As shown, the precipitation had both positive and negative serial correlations. The highest and at the same time the significant serial correlation of 0.260 was obtained at the Baicheng station, while the lowest serial correlation of -0.104 was detected at the Wuqia station.

Lag-1 serial correlation coefficients for seasonal precipitation data at the observed stations during the period 19602010 are presented in Table 5. As shown, a positive serial correlation was found in the spring, summer, autumn, and winter series at $77.8 \%, 88.9 \%, 66.7 \%$, and $77.8 \%$ of the stations, respectively. The significant serial correlation was detected in the autumn at Aheqi station. Trends of precipitation are considered statistically at the 5\% significance level using the

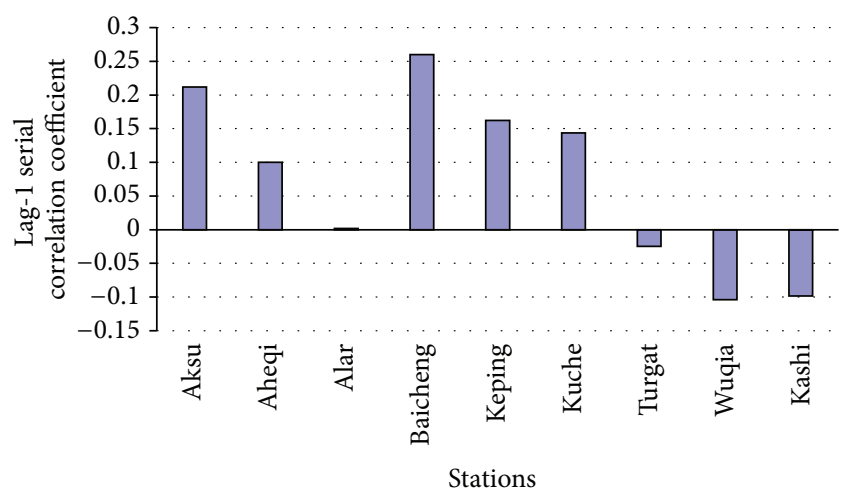

FIGURE 5: Lag-1 serial correlation coefficient for the precipitation at the synoptic stations.

TABLE 5: Lag-1 serial correlation coefficients for seasonal precipitation data.

\begin{tabular}{lcccc}
\hline Station name & Spring & Summer & Autumn & Winter \\
\hline Aksu & 0.102 & 0.105 & -0.042 & 0.181 \\
Aheqi & 0.199 & 0.009 & 0.395 & 0.102 \\
Alar & -0.006 & 0.147 & -0.108 & -0.078 \\
Baicheng & 0.192 & 0.160 & 0.140 & 0.187 \\
Keping & 0.059 & 0.167 & 0.014 & 0.113 \\
Kuche & 0.106 & 0.035 & -0.077 & 0.077 \\
Turgat & 0.028 & 0.019 & 0.090 & 0.163 \\
Wuqia & -0.020 & 0.100 & 0.131 & -0.068 \\
Kashi & 0.054 & -0.050 & 0.090 & 0.019 \\
\hline
\end{tabular}

Mann-Kendall test and the Spearman's Rho test. When a significant trend is identified by two statistical methods, the trend is presented in bold character in Table 6 .

The results of the statistical tests for the monthly precipitation series during the period 1960-2010 are summarized in Table 6. As shown, the precipitation in Baicheng station had the significant increasing trend in June and September. The significant increasing trend was also detected at the 


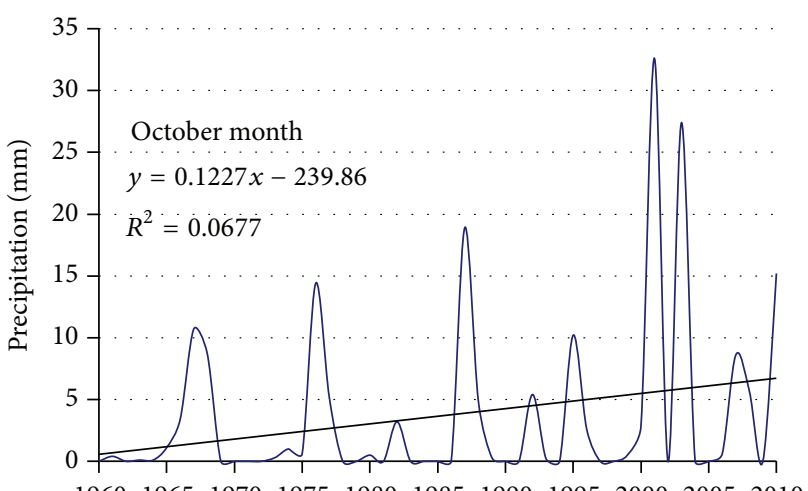

$\begin{array}{lllllllllll}1960 & 1965 & 1970 & 1975 & 1980 & 1985 & 1990 & 1995 & 2000 & 2005 & 2010\end{array}$

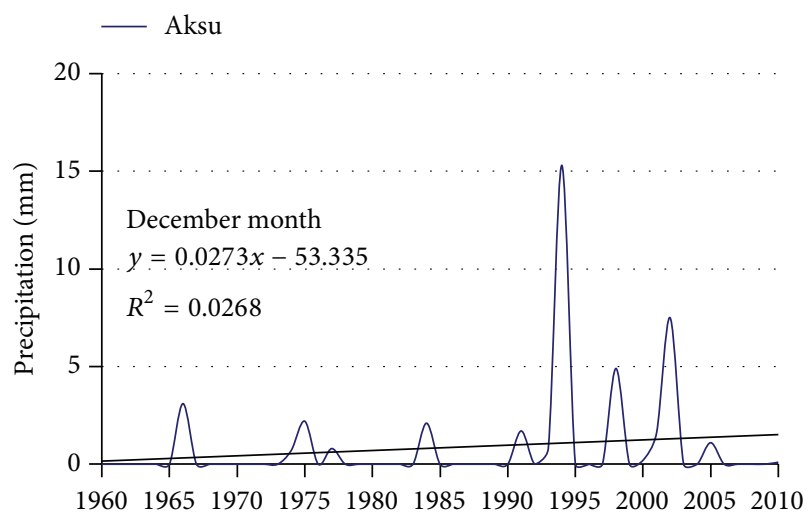

- Alar
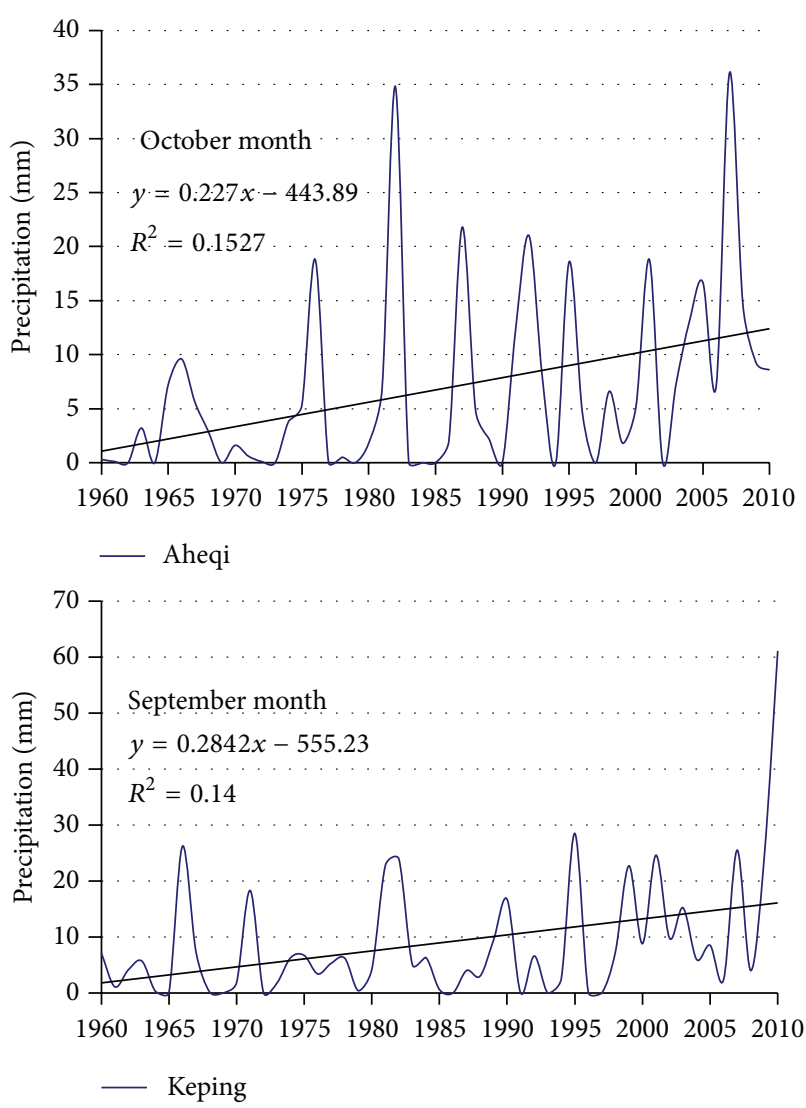

FIGURE 6: Variations of monthly precipitation in stations with the significant trends during the study period.

Kuche station in January, June, and December. There was no decreasing trend. Besides, A statistically significant trend $Z_{S}=2.380$ was detected in September at the Aheqi station before eliminating the effect of serial correlation. After removing lag-1 serial correlation effect, an insignificant trend of $Z_{S}=1.673$ was obtained. Furthermore, an insignificant trend $Z_{D}=1.633$ was detected in January at the Kuche station before eliminating the effect of serial correlation. After removing lag-1 serial correlation effect a significant trend of $Z_{S}=2.893$ was obtained.

Seasonal and annual trends of precipitation obtained by statistical methods are given in Table 7 . According to these results, the increasing trends in annual precipitation series were detected at Aheqi, Baicheng, Keping, and Kuche, while there is no significant trend for other stations which is consistent with our analysis in Section 3.1. On annual level, precipitation quantities are increasing, with the highest increase in winter.

For the seasonal scale, there were increasing trends in summer and winter precipitation series. The decreasing precipitation trend was found in the spring and autumn series at $33 \%$ and $11 \%$ of the stations, respectively. Besides, the significant increasing trends were found at Aheqi and Kashi in autumn and at Alar and Kuche in winter. Furthermore, the significant increasing trends were detected at Baicheng in summer, autumn, and winter. The precipitation of Keping also had increasing trends in summer and autumn.
3.5. Analysis of SPI-12. Time series of SPI-12 at the 9 synoptic stations during the period 1960-2010 are shown in Figure 7. Characteristics of drought at 12-month time scale are shown in Table 8. It should be observed that the most severe drought of Aheqi and Alar was 1975, while that of Keping and Wuqia occurred in 1985. Besides, the most severe drought year was 1976 at Bacheng station and 1986 at Aksu station. The Wuqia station had the lowest SPI-12 with -2.5986 in 1985 . The number of drought years during the observed period at the stations is presented in Table 8. According to the results, the total drought years ranged between 14 (at Wuqia and Kashi station) and 19 (at Alar station). Almost $32.2 \%$ of the observed years were drought years at all the 9 stations.

Lag-1 serial correlation coefficient for the SPI-12 at the observed synoptic stations is illustrated in Figure 8. The highest and at the same time the significant positive serial correlation coefficient of 0.2676 was detected at the Aksu station. On the other hand, negative values were observed at the Turgat, Wuqia, and Kashi stations.

The results of the Mann-Kendall and Spearman's Rho tests for the SPI-12 series are presented in Figure 9. It can be noted that all stations have the increasing trend. The significant trends were detected at Aheqi, Baicheng, Keping, and Kuche stations.

Although a significantly increasing trend was detected in the SPI-12 series of all the observed stations, it can be determined that the western regions of Aksu River Basin have 


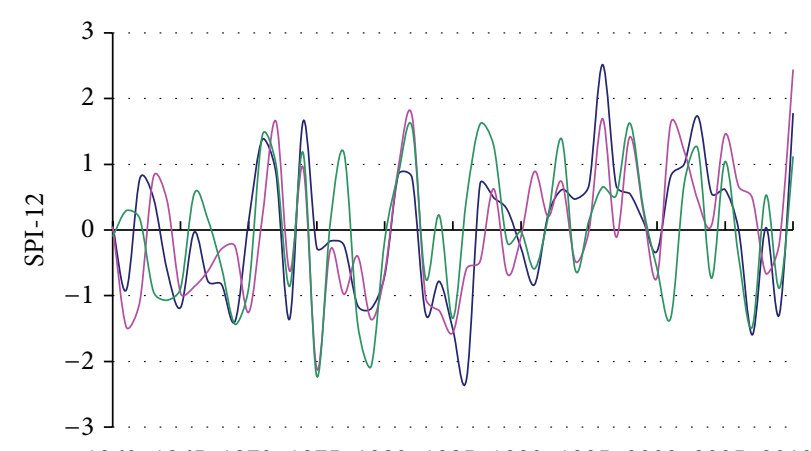

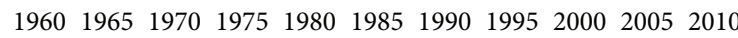

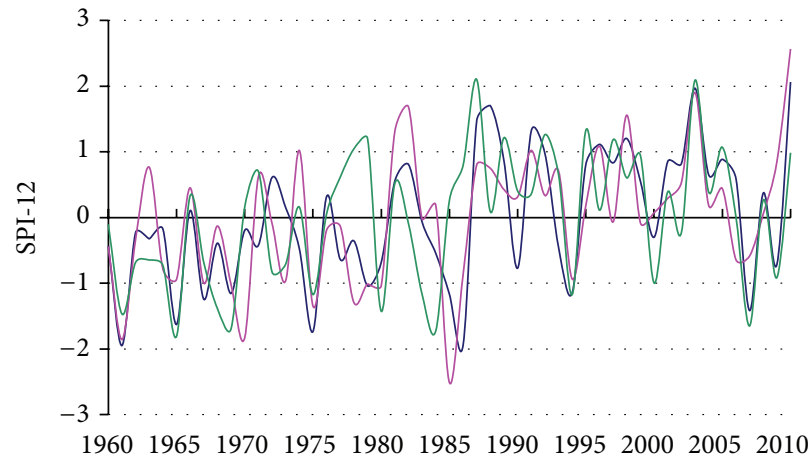

_ Baicheng
Keping
Kuche

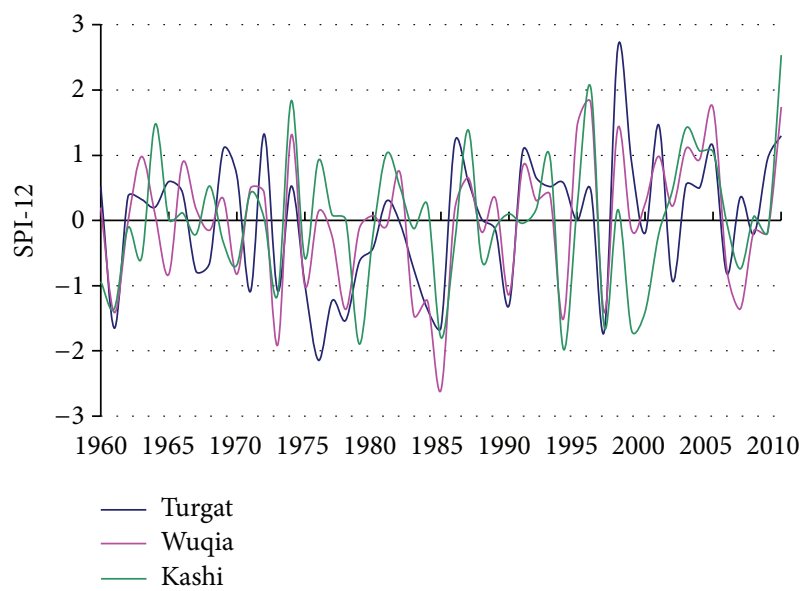

Figure 7: Time series of SPI-12 at the 9 synoptic stations.

become much drier than the other parts during the period 1960-2010. This had significant impact on agriculture and water supply.

\section{Conclusions}

Based on the analysis of the variation of precipitation and drought indices and correlation in the multisites in this study area during 1960-2010, the following conclusions can be drawn from this study.

Precipitation trends and drought behavior at monthly, seasonal, and annual time scale in Aksu River Basin between 1960 and 2010 were investigated, respectively. In order to achieve this, monthly, seasonal, and annual precipitation data from 9 Serbian synoptic stations were analyzed using the Mann-Kendall test and the Spearman's Rho test after eliminating the effect of significant lag-1 serial correlation from the time series. Besides, aridity and annual rainfall variability indices were estimated.

According to these results, two main annual drought periods were detected (1978-1979 and 1983-1986), while the dry year was 1975 and 1985 at almost all of the stations. The monthly analysis of precipitation series suggests that all stations had increasing trend in July, October, and December,

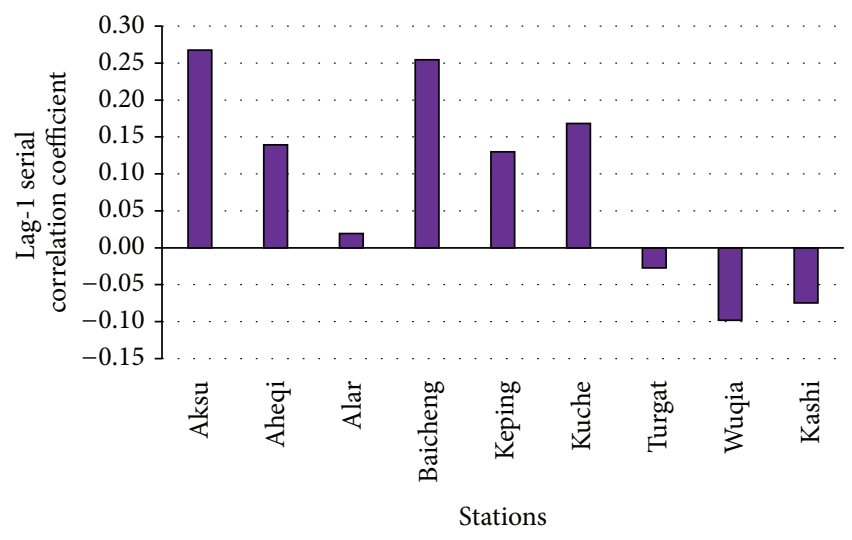

FIgURE 8: Lag-1 serial correlation coefficient for the SPI-12 at the 9 synoptic stations.

while both increasing and decreasing trends were found in other months. At the seasonal scale, there were increasing trends in summer and winter precipitation series. The decreasing precipitation trend was found in the spring and autumn series at $33 \%$ and $11 \%$ of the stations, respectively. 
TABLE 6: Results of the statistical tests for the monthly precipitation during the period 1960-2010.

\begin{tabular}{|c|c|c|c|c|c|c|c|c|c|c|c|c|c|}
\hline \multirow{2}{*}{ Station } & \multirow{2}{*}{ Test } & \multicolumn{12}{|c|}{ Month } \\
\hline & & January & February & March & April & May & June & July & August & September & October & November & December \\
\hline \multirow{3}{*}{ Aksu } & $Z_{S}$ & 0.233 & 0.760 & 0.411 & -0.579 & 0.276 & 1.755 & 0.796 & -0.926 & 1.365 & 0.976 & 0.000 & 1.588 \\
\hline & $Z_{D}$ & 0.410 & 0.884 & 0.586 & -0.279 & 0.232 & 2.014 & 0.793 & -0.890 & 1.318 & 1.203 & 0.789 & 2.060 \\
\hline & $b$ & 0.023 & 0.060 & 0.058 & 0.016 & 0.011 & 0.184 & 0.036 & -0.075 & 0.138 & 0.122 & -0.008 & 0.038 \\
\hline \multirow{3}{*}{ Aheqi } & $Z_{S}$ & 0.139 & 0.383 & 0.789 & 0.545 & 0.016 & -0.244 & 1.576 & 0.390 & 1.673 & $2.795^{*}$ & 0.798 & 1.088 \\
\hline & $Z_{D}$ & 0.159 & 0.319 & 0.816 & 0.615 & 0.026 & -0.146 & 1.766 & 0.524 & 1.729 & $3.249^{*}$ & 1.020 & 1.250 \\
\hline & $b$ & 0.014 & 0.019 & 0.129 & 0.019 & 0.058 & -0.054 & 0.513 & 0.236 & 0.877 & 0.227 & -0.001 & 0.024 \\
\hline \multirow{3}{*}{ Alar } & $Z_{S}$ & 1.454 & 1.175 & -0.102 & -0.171 & 0.073 & 1.276 & 1.186 & -0.016 & -0.552 & 0.026 & 0.603 & 1.523 \\
\hline & $Z_{D}$ & 1.964 & $2.166^{*}$ & 0.658 & 0.494 & -0.025 & 1.439 & 1.309 & 0.021 & -0.399 & 0.521 & $2.088^{*}$ & $2.747^{*}$ \\
\hline & $b$ & 0.025 & 0.028 & 0.023 & -0.014 & -0.050 & 0.078 & 0.106 & 0.069 & -0.067 & 0.013 & -0.003 & 0.027 \\
\hline \multirow{3}{*}{ Baicheng } & $Z_{S}$ & 1.206 & 1.007 & 0.253 & 0.262 & 1.089 & $2.193^{*}$ & 1.901 & 1.324 & $2.161^{*}$ & 1.322 & 0.886 & 1.605 \\
\hline & $Z_{D}$ & 1.394 & 0.786 & 0.247 & 0.339 & 1.155 & $2.477^{\star}$ & 1.926 & 1.175 & $2.207^{*}$ & 1.339 & 1.313 & 1.783 \\
\hline & $b$ & 0.042 & 0.083 & 0.037 & -0.025 & 0.077 & 0.268 & 0.234 & 0.122 & 0.228 & 0.231 & 0.089 & 0.042 \\
\hline \multirow{3}{*}{ Keping } & $Z_{S}$ & 0.311 & 1.171 & 1.308 & -0.198 & -0.073 & 0.918 & 1.706 & 1.405 & $2.278^{*}$ & 1.363 & -0.249 & 0.937 \\
\hline & $Z_{D}$ & 0.525 & 1.064 & 1.665 & -0.185 & -0.026 & 0.999 & 1.849 & 1.485 & $2.447^{*}$ & 1.726 & 1.112 & 1.482 \\
\hline & $b$ & 0.045 & 0.037 & 0.102 & 0.009 & -0.014 & 0.112 & 0.273 & 0.367 & 0.284 & 0.079 & -0.012 & 0.031 \\
\hline \multirow{3}{*}{ Kuche } & $Z_{S}$ & $2.633^{*}$ & 0.919 & -0.694 & 0.679 & 0.699 & $2.437^{*}$ & 0.999 & 1.357 & 0.553 & 0.513 & 1.896 & $2.533^{*}$ \\
\hline & $Z_{D}$ & $2.893^{*}$ & 1.024 & -0.541 & 0.773 & 0.808 & $2.747^{*}$ & 1.057 & 1.279 & 0.476 & 0.651 & $2.626^{*}$ & $3.113^{*}$ \\
\hline & $b$ & 0.048 & 0.052 & -0.036 & 0.023 & 0.106 & 0.207 & 0.061 & 0.063 & 0.019 & 0.013 & -0.010 & 0.039 \\
\hline \multirow{3}{*}{ Turgat } & $Z_{S}$ & 0.033 & -0.455 & 0.723 & 0.227 & -0.382 & 1.527 & 0.796 & 0.398 & -0.106 & $2.713^{*}$ & 0.122 & $2.211^{*}$ \\
\hline & $Z_{D}$ & -0.046 & -0.428 & 0.619 & 0.254 & -0.387 & 1.498 & 0.794 & 0.392 & -0.066 & $2.810^{*}$ & 0.190 & $2.307^{*}$ \\
\hline & $b$ & -0.003 & -0.018 & 0.019 & 0.091 & -0.058 & 0.285 & 0.164 & 0.130 & 0.023 & 0.253 & -0.006 & 0.093 \\
\hline \multirow{3}{*}{ Wuqia } & $Z_{S}$ & 0.708 & -1.122 & -0.228 & -0.041 & 0.195 & 1.600 & 1.787 & -0.024 & 0.699 & $2.847^{*}$ & -0.016 & 1.027 \\
\hline & $Z_{D}$ & 0.699 & -1.394 & -0.375 & -0.097 & 0.007 & 1.822 & $2.194^{*}$ & -0.008 & 0.677 & $2.983^{*}$ & -0.151 & 1.176 \\
\hline & $b$ & 0.032 & -0.039 & -0.048 & 0.011 & -0.092 & 0.465 & 0.407 & -0.076 & 0.141 & 0.239 & -0.015 & 0.029 \\
\hline \multirow{3}{*}{ Kashi } & $Z_{S}$ & 0.507 & -0.638 & 1.455 & -0.156 & 0.602 & 0.999 & 1.406 & 0.268 & 1.223 & $3.249^{*}$ & 0.365 & 1.035 \\
\hline & $Z_{D}$ & 0.685 & -0.387 & 1.758 & -0.164 & 0.401 & 1.146 & 1.327 & 0.199 & 1.294 & $3.908^{*}$ & 1.071 & 1.430 \\
\hline & $b$ & 0.048 & -0.015 & 0.106 & -0.058 & -0.115 & 0.096 & 0.111 & -0.025 & 0.104 & 0.170 & 0.024 & 0.020 \\
\hline
\end{tabular}

$Z_{S}$ : Mann-Kendall test, $Z_{D}$ : Spearman's Rho test, and $b$ : slope of linear regression.

Bold characters represent trends identified by 2 statistical methods together.

* Statistically significant trends at the $5 \%$ significance level.
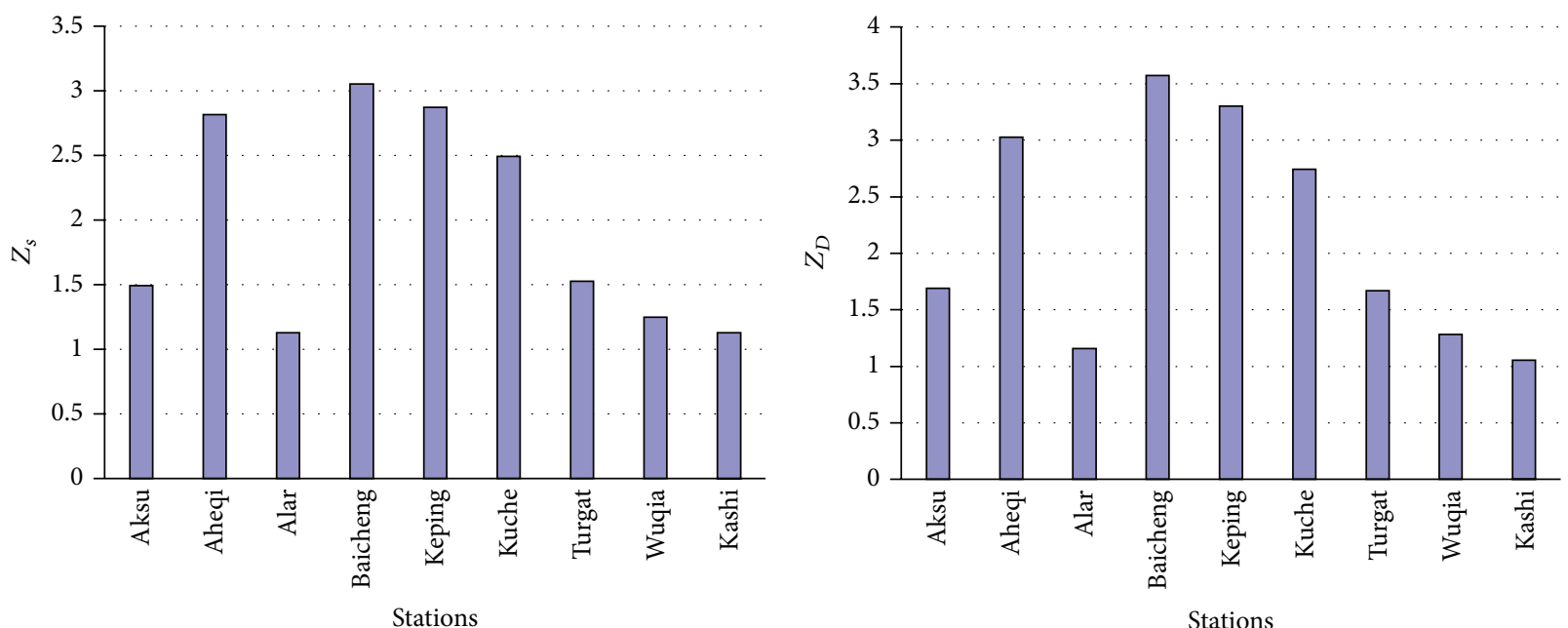

FIgURE 9: Mann-Kendall test $\left(Z_{S}\right)$ and Spearman's Rho test $\left(Z_{D}\right)$ for the SPI-12 series. 
TABLE 7: Results of the statistical tests for seasonal and annual precipitation during the period 1960-2010.

\begin{tabular}{|c|c|c|c|c|c|c|}
\hline \multirow{2}{*}{ Station } & \multirow{2}{*}{ Test } & \multicolumn{5}{|c|}{ Season } \\
\hline & & Spring & Summer & Autumn & Winter & Annual \\
\hline \multirow{3}{*}{ Aksu } & $Z_{S}$ & 0.341 & 0.780 & 1.673 & 1.154 & 1.495 \\
\hline & $Z_{D}$ & 0.295 & 0.952 & 1.696 & 1.264 & 1.690 \\
\hline & $b$ & 0.084 & 0.145 & 0.253 & 0.125 & 0.603 \\
\hline \multirow{3}{*}{ Aheqi } & $Z_{S}$ & 0.309 & 1.056 & $2.209^{*}$ & 0.739 & $2.819^{*}$ \\
\hline & $Z_{D}$ & 0.434 & 1.106 & $2.338^{*}$ & 0.529 & $3.026^{\star}$ \\
\hline & $b$ & 0.206 & 0.695 & 1.103 & 0.055 & 2.062 \\
\hline \multirow{3}{*}{ Alar } & $Z_{S}$ & -0.520 & 1.592 & -0.390 & 1.947 & 1.129 \\
\hline & $Z_{D}$ & -0.567 & 1.793 & -0.325 & $2.152^{*}$ & 1.159 \\
\hline & $b$ & -0.041 & 0.253 & -0.057 & 0.083 & 0.235 \\
\hline \multirow{3}{*}{ Baicheng } & $Z_{S}$ & 0.390 & $2.713^{*}$ & $2.266^{*}$ & $2.112^{*}$ & $2.193^{*}$ \\
\hline & $Z_{D}$ & 0.392 & $3.029^{*}$ & $2.444^{*}$ & $2.214^{*}$ & $2.620^{*}$ \\
\hline & $b$ & 0.089 & 0.624 & 0.548 & 0.166 & 1.427 \\
\hline \multirow{3}{*}{ Keping } & $Z_{S}$ & 0.244 & $2.372^{*}$ & $2.429^{*}$ & 1.357 & $2.875^{*}$ \\
\hline & $Z_{D}$ & 0.404 & $2.567^{*}$ & $2.552^{*}$ & 1.483 & $3.300^{*}$ \\
\hline & $b$ & 0.097 & 0.752 & 0.351 & 0.113 & 1.313 \\
\hline \multirow{3}{*}{ Kuche } & $Z_{S}$ & 0.430 & 1.852 & 0.423 & $2.145^{*}$ & $2.494^{*}$ \\
\hline & $Z_{D}$ & 0.416 & $2.050^{*}$ & 0.263 & $2.274^{*}$ & $2.743^{*}$ \\
\hline & $b$ & 0.093 & 0.331 & 0.023 & 0.141 & 0.585 \\
\hline \multirow{3}{*}{ Turgat } & $Z_{S}$ & 0.195 & 1.503 & 1.194 & 1.803 & 1.527 \\
\hline & $Z_{D}$ & 0.283 & 1.379 & 1.225 & 1.874 & 1.667 \\
\hline & $b$ & 0.052 & 0.579 & 0.270 & 0.099 & 0.973 \\
\hline \multirow{3}{*}{ Wuqia } & $Z_{S}$ & -0.260 & 1.462 & 1.698 & 0.065 & 1.251 \\
\hline & $Z_{D}$ & -0.342 & 1.599 & 1.579 & 0.062 & 1.281 \\
\hline & $b$ & -0.129 & 0.796 & 0.365 & 0.014 & 1.054 \\
\hline \multirow{3}{*}{ Kashi } & $Z_{S}$ & -0.195 & 1.121 & $2.527^{*}$ & 0.390 & 1.129 \\
\hline & $Z_{D}$ & -0.223 & 1.150 & $2.547^{*}$ & 0.499 & 1.055 \\
\hline & $b$ & -0.067 & 0.182 & 0.297 & 0.041 & 0.466 \\
\hline
\end{tabular}

$Z_{S}$ : Mann-Kendall test, $Z_{D}$ : Spearman's Rho test, and $b$ : slope of linear regression.

Bold characters represent trends identified by 2 statistical methods together.

* Statistically significant trends at the $5 \%$ significance level.

TABLE 8: Characteristics of droughts at 12-month time scale.

\begin{tabular}{|c|c|c|c|c|c|c|}
\hline \multirow{2}{*}{ Station } & \multicolumn{2}{|c|}{ The most severe drought } & \multicolumn{4}{|c|}{ Number of drought years during the observed period } \\
\hline & SPI & Year & Near normal & Moderate & Severe/extreme & Total \\
\hline Aksu & -2.2748 & 1986 & 7 & 7 & 3 & 17 \\
\hline Aheqi & -2.1138 & 1975 & 10 & 6 & 2 & 18 \\
\hline Alar & -2.2262 & 1975 & 11 & 6 & 2 & 19 \\
\hline Keping & -2.5112 & 1985 & 8 & 5 & 3 & 16 \\
\hline Baicheng & -1.9470 & 1961 & 5 & 6 & 4 & 15 \\
\hline Kuche & -1.8056 & 1965 & 8 & 6 & 4 & 18 \\
\hline Turgat & -2.1432 & 1976 & 7 & 5 & 5 & 17 \\
\hline Wuqia & -2.5986 & 1985 & 3 & 8 & 3 & 14 \\
\hline Kashi & -1.9757 & 1994 & 6 & 3 & 5 & 14 \\
\hline
\end{tabular}

For the SPI-12, all stations have the increasing trend. The significant trends were detected at Aheqi, Baicheng, Keping, and Kuche stations (As shown in Figure 6). Based on the analysis of trends of precipitation and drought behavior, precipitation in Aksu River Basin had an increasing trend.
And drought condition, including drought severity and drought duration, became better. The analyzed results of precipitation and SPI-12 series can be helpful for basinscale water resources management, agricultural production. Further research in analyzing the spatial variation of 
precipitation trends and the relationship with the climate change projection is recommended. Moreover, the future work will be oriented into developing an information system for monitoring and early drought warning.

\section{Conflict of Interests}

The authors declare that there is no conflict of interests.

\section{Authors' Contribution}

Yuhu Zhang and Wanyuan Cai prepared the paper. Yuhu Zhang, Qiuhua Chen, and Kaili Liu made the data processing. Yunjun Yao contributed to the discussion.

\section{Acknowledgments}

The financial support of this work has been provided by the National Science and Technology Support Plan during the 12th Five-Year Plan Period of China projects (Grants nos. 2013BAC10B01 and 2012BAC19B03) and State Key Laboratory of Desert and Oasis Ecology, Xinjiang Institute of Ecology and Geography, Chinese Academy of Sciences downscaling correction model for satellite precipitation in mountainous area of Xinjiang. It is also realized as a part of the Project "Statistical Analysis and Information Extraction of HighDimensional Complicate Data" jointly funded by Scientific Research Project of Beijing Educational Committee (no. KZ201410028030). The authors also would like to thank the editors and the anonymous reviewers for their crucial comments, which will improve the quality of this paper.

\section{References}

[1] H. Hisdal, K. Stahl, L. M. Tallaksen, and S. Demuth, "Have streamflow droughts in Europe become more severe or frequent?" International Journal of Climatology, vol. 21, no. 3, pp. 317-333, 2001.

[2] M. Gocic and S. Trajkovic, "Analysis of precipitation and drought data in Serbia over the period 1980-2010," Journal of Hydrology, vol. 494, pp. 32-42, 2013.

[3] M. Gemmer, S. Becker, and T. Jiang, "Observed monthly precipitation trends in China 1951-2002," Theoretical and Applied Climatology, vol. 77, no. 1-2, pp. 39-45, 2004.

[4] T. Partal and E. Kahya, "Trend analysis in Turkish precipitation data," Hydrological Processes, vol. 20, no. 9, pp. 2011-2026, 2006.

[5] Q. Liu, Z. Yang, and B. Cui, "Spatial and temporal variability of annual precipitation during 1961-2006 in Yellow River Basin, China," Journal of Hydrology, vol. 361, no. 3-4, pp. 330-338, 2008.

[6] P. G. Oguntunde, B. J. Abiodun, and G. Lischeid, "Rainfall trends in Nigeria, 1901-2000," Journal of Hydrology, vol. 411, no. 3-4, pp. 207-218, 2011.

[7] H. Tabari and P. H. Talaee, "Temporal variability of precipitation over Iran: 1966-2005, Journal of Hydrology, vol. 396, no. 3-4, pp. 313-320, 2011.

[8] H. Tabari, H. Abghari, and P. Hosseinzadeh Talaee, "Temporal trends and spatial characteristics of drought and rainfall in arid and semiarid regions of Iran," Hydrological Processes, vol. 26, no. 22, pp. 3351-3361, 2012.
[9] E. E. Moreira, C. A. Coelho, A. A. Paulo, L. S. Pereira, and J. T. Mexia, "SPI-based drought category prediction using loglinear models," Journal of Hydrology, vol. 354, no. 1-4, pp. 116-130, 2008.

[10] A. A. Paulo and L. S. Pereira, "Stochastic prediction of drought class transitions," Water Resources Management, vol. 22, no. 9, pp. 1277-1296, 2008.

[11] S. Shahid, "Spatial and temporal characteristics of droughts in the western part of Bangladesh," Hydrological Processes, vol. 22, no. 13, pp. 2235-2247, 2008.

[12] D. Khalili, T. Farnoud, H. Jamshidi, A. A. Kamgar-Haghighi, and S. Zand-Parsa, "Comparability analyses of the SPI and RDI meteorological drought indices in different climatic zones," Water Resources Management, vol. 25, no. 6, pp. 1737-1757, 2011.

[13] A. K. Mishra and V. P. Singh, "A review of drought concepts," Journal of Hydrology, vol. 391, no. 1-2, pp. 202-216, 2010.

[14] Y. H. Ding, G. Y. Ren, Z. C. Zhao et al., "Detection, causes and projection of climate change over China: an overview of recent progress," Advances in Atmospheric Sciences, vol. 24, no. 6, pp. 954-971, 2007.

[15] Y. Shi, Y. Shen, E. Kang et al., "Recent and future climate change in northwest China," Climatic Change, vol. 80, no. 3-4, pp. 379393, 2007.

[16] H. Weng, K.-M. Lau, and Y. Xue, "Multi-scale summer rainfall variability over China and its long-term link to global sea surface temperature variability," Journal of the Meteorological Society of Japan, vol. 77, no. 4, pp. 845-857, 1999.

[17] C.-P. Chang, Y. Zhang, and T. Li, "Interannual and interdecadal variations of the East Asian summer monsoon and tropical pacific SSTs. Part I: Roles of the subtropical ridge," Journal of Climate, vol. 13, no. 24, pp. 4310-4325, 2000.

[18] G. Ren, H. Wu, and Z. Chen, "Spatial patterns of change trend in rainfall of China," Quarterly Journal of Applied Meteorology, vol. 11, pp. 322-330, 2000.

[19] Y. Ding, Z. Wang, and Y. Sun, "Inter-decadal variation of the summer precipitation in east China and its association with decreasing Asian summer monsoon. Part I: observed evidences," International Journal of Climatology, vol. 28, no. 9, pp. 1139-1161, 2008.

[20] Y. Lei, B. Hoskins, and J. Slingo, "Exploring the interplay between natural decadal variability and anthropogenic climate change in summer rainfall over China. Part I: observational evidence," Journal of Climate, vol. 24, no. 17, pp. 4584-4599, 2011.

[21] R. H. Zhang, B. Y. Wu, P. Zhao, and J. Han, “The decadal shift of the summer climate in the late 1980s over East China and its possible causes," Acta Meteorological Sinica, vol. 66, pp. 697706, 2008.

[22] P. Zhao, Y. Song, and R. C. Yu, "Long-term changes in rainfall over Eastern China and large-scale atmospheric circulation associated with recent global warming," Journal of Climate, vol. 23, no. 6, pp. 1544-1562, 2010.

[23] D. Yihui, R. Guoyu, S. Guangyu et al., "China’s national assessment report on climate change (I): climate change in China and the future trend," Advances in Climate Change Research, vol. 3, supplement, pp. 1-5, 2007.

[24] K. E. Trenberth and P. D. Jones, "Observations: surface and atmospheric climate change," in Climate Change 2007: The Physical Science Basis, S. Solomon, D. Qin, M. Manning et al., Eds., chapter 3, pp. 235-336, Cambridge University Press, Cambridge, UK, 2007. 
[25] H. Ye and R. Lu, "Subseasonal variation in ENSO-related east asian rainfall anomalies during summer and its role in weakening the relationship between the ENSO and summer rainfall in eastern china since the late 1970s," Journal of Climate, vol. 24, no. 9, pp. 2271-2284, 2011.

[26] A. Duan, M. Wang, Y. Lei, and Y. Cui, "Trends in summer rainfall over china associated with the Tibetan Plateau sensible heat source during 1980-2008," Journal of Climate, vol. 26, no. 1, pp. 261-275, 2013.

[27] Z. Zhu, T. Li, and J. He, "Out-of-phase relationship between Boreal spring and summer decadal rainfall changes in Southern China," Journal of Climate, vol. 27, no. 3, pp. 1083-1099, 2014.

[28] Y. N. Chen and Z. X. Xu, "Plausible impact of global climate change on water resources in the Tarim River Basin," Science in China, Series D: Earth Sciences, vol. 48, no. 1, pp. 65-73, 2005.

[29] H. Li, Z. Jiang, and Q. Yang, "Association of north atlantic oscillations with aksu river runoff in China," Journal of Geographical Sciences, vol. 19, no. 1, pp. 12-24, 2009.

[30] S. Zhang, S. Liu, X. Mo, C. Shu, Y. Sun, and C. Zhang, "Assessing the impact of climate change on reference evapotranspiration in Aksu River Basin," Acta Geographica Sinica, vol. 65, no. 11, pp. 1363-1370, 2010.

[31] S. Zhang, S. Liu, X. Mo, C. Shu, Y. Sun, and C. Zhang, "Assessing the impact of climate change on potential evapotranspiration in Aksu River Basin," Journal of Geographical Sciences, vol. 21, no. 4, pp. 609-620, 2011.

[32] B. Li, Y. Chen, X. Shi, Z. Chen, and W. Li, “Temperature and precipitation changes in different environments in the arid region of northwest China," Theoretical and Applied Climatology, vol. 112, no. 3-4, pp. 589-596, 2013.

[33] H. Wang, Y. Chen, S. Xun, D. Lai, Y. Fan, and Z. Li, "Changes in daily climate extremes in the arid area of northwestern China," Theoretical and Applied Climatology, vol. 112, no. 1-2, pp. 15-28, 2013.

[34] S. Han and H. Hu, "Spatial variations and temporal changes in potential evaporation in the Tarim Basin, Northwest China (1960-2006): influenced by irrigation?" Hydrological Processes, vol. 26, no. 20, pp. 3041-3051, 2012.

[35] Q. Zhang, J. Li, V. P. Singh, and Y. Bai, "SPI-based evaluation of drought events in Xinjiang, China," Natural Hazards, vol. 64, no. 1, pp. 481-492, 2012.

[36] Y. N. Chen, K. Takeuchi, C. Xu, Y. P. Chen, and Z. X. Xu, "Regional climate change and its effects on river runoff in the Tarim Basin, China," Hydrological Processes, vol. 20, no. 10, pp. 2207-2216, 2006.

[37] Y.-N. Chen, W.-H. Li, C.-C. Xu, and X.-M. Hao, "Effects of climate change on water resources in Tarim River Basin, Northwest China," Journal of Environmental Sciences, vol. 19, no. 4, pp. 488-493, 2007.

[38] C. Yaning, X. Changchun, H. Xingming et al., "Fifty-year climate change and its effect on annual runoff in the Tarim River Basin, China," Quaternary International, vol. 208, no. 1-2, pp. 53-61, 2009.

[39] H. F. Lee and D. D. Zhang, "Relationship between NAO and drought disasters in northwestern China in the last millennium," Journal of Arid Environments, vol. 75, no. 11, pp. 11141120, 2011.

[40] H. Ling, H. Xu, and J. Fu, "Changes in intra-annual runoff and its response to climate change and human activities in the headstream areas of the Tarim River Basin, China," Quaternary International, vol. 336, no. 26, pp. 158-170, 2014.
[41] R. Ouyang, W. Cheng, W. Wang, Y. Jiang, Y. Zhang, and Y. Wang, "Research on runoff forecast approaches to the Aksu River basin," Science in China, Series D: Earth Sciences, vol. 50, no. 1, supplement, pp. 16-25, 2007.

[42] X. L. Wang, "Comment on 'detection of undocumented change point: a revision of the two-phase regression model', Journal of Climate, vol. 16, no. 20, pp. 3383-3385, 2003.

[43] World Meteorological Organization (WMO), Drought and Agriculture, WMO/TN 138, World Meteorological Organization (WMO), Geneva, Switzerland, 1975.

[44] United Nations Environmental Programme (UNEP), World Atlas of Desertification, United Nations Environmental Programme (UNEP), 1992.

[45] R. G. Allen, M. E. Jensen, J. L. Wright, and R. D. Burman, "Operational estimates of reference evapotranspiration," Agronomy Journal, vol. 81, no. 4, pp. 650-662, 1989.

[46] R. G. Allen, L. S. Pereira, D. Raes, and M. Smith, "Crop evapotranspiration. Guidelines for computing crop water requirements," FAO Irrigation and Drainage Paper 56, Food and Agriculture Organization of the United Nation, Rome, Italy, 1998.

[47] M. Bannayan, S. Sanjani, A. Alizadeh, S. S. Lotfabadi, and A. Mohamadian, "Association between climate indices, aridity index, and rainfed crop yield in Northeast of Iran," Field Crops Research, vol. 118, no. 2, pp. 105-114, 2010.

[48] R. R. Heim Jr., "A review of twentieth-century drought indices used in the United States," Bulletin of the American Meteorological Society, vol. 83, no. 8, pp. 1149-1165, 2002.

[49] M. V. K. Sivakumar, R. P. Motha, D. A. Wilhite, and D. A. Wood, Agricultural Drought Indices: Proceedings of an Expert Meeting, 2-4 June 2010, Murcia, Spain, World Meteorological Organization, Geneva, Switzerland, 2010.

[50] T. B. McKee, N. J. Doesken, and J. Kleist, "The relationship of drought frequency and duration to time scales," in Proceedings of the 8th Conference on Applied Climatology, pp. 179-184, Anaheim, Calif, USA, January 1993.

[51] T. B. McKee, N. J. Doesken, and J. Kleist, "Drought monitoring with multiple time scales," in Proceedings of the 9th Conference on Applied Climatology, pp. 233-236, American Meteorological Society, Boston, Mass, USA, January 1995.

[52] K. E. Logan, N. A. Brunsell, A. R. Jones, and J. J. Feddema, "Assessing spatiotemporal variability of drought in the U.S. central plains," Journal of Arid Environments, vol. 74, no. 2, pp. 247-255, 2010.

[53] M. J. Hayes, M. D. Svoboda, D. A. Wilhite, and O. V. Vanyarkho, "Monitoring the 1996 drought using the standardized precipitation index," Bulletin of the American Meteorological Society, vol. 80, no. 3, pp. 429-438, 1999.

[54] R. A. Seiler, M. Hayes, and L. Bressan, "Using the standardized precipitation index for flood risk monitoring," International Journal of Climatology, vol. 22, no. 11, pp. 1365-1376, 2002.

[55] H. C. S. Thom, "A note on the gamma distribution," Monthly Weather Review, vol. 86, no. 4, pp. 117-122, 1958.

[56] H. C. S. Thom, "Some methods of climatological analysis," WMO Technical Note 81, Secretariat of the World Meteorological Organization, Geneva, Switzerland, 1966.

[57] D. C. Edwards and T. B. McKee, "Characteristics of 20th century drought in the United States at multiple scales," Atmospheric Science Paper 634, 1997.

[58] M. Abramowitz and I. A. Stegun, Handbook of Mathematical Functions, Dover Publications, New York, NY, USA, 1965. 
[59] I. Bordi, S. Frigio, P. Parenti, A. Speranza, and A. Sutera, "The analysis of the Standardized Precipitation Index in the Mediterranean area: large-scale patterns," Annals of Geophysics, vol. 44, no. 5-6, pp. 965-978, 2001.

[60] B. Lloyd-Hughes and M. A. Saunders, "A drought climatology for Europe," International Journal of Climatology, vol. 22, no. 13, pp. 1571-1592, 2002.

[61] B. Bonaccorso, I. Bordi, A. Cancelliere, G. Rossi, and A. Sutera, "Spatial variability of drought: an analysis of the SPI in Sicily," Water Resources Management, vol. 17, no. 4, pp. 273-296, 2003.

[62] T. Raziei, B. Saghafian, A. A. Paulo, L. S. Pereira, and I. Bordi, "Spatial patterns and temporal variability of drought in Western Iran," Water Resources Management, vol. 23, no. 3, pp. 439-455, 2009.

[63] M. Gocic and S. Trajkovic, "Analysis of changes in meteorological variables using Mann-Kendall and Sen's slope estimator statistical tests in Serbia," Global and Planetary Change, vol. 100, pp. 172-182, 2013.

[64] M. A. Kohler, "Double-mass analysis for testing the consistency of records and for making adjustments," Bulletin of the American Meteorological Society, vol. 30, pp. 188-189, 1949.

[65] T. Niedźwiedź, R. Twardosz, and A. Walanus, "Long-term variability of precipitation series in east central Europe in relation to circulation patterns," Theoretical and Applied Climatology, vol. 98, no. 3-4, pp. 337-350, 2009.

[66] A. A. Paulo, R. D. Rosa, and L. S. Pereira, "Climate trends and behaviour of drought indices based on precipitation and evapotranspiration in Portugal," Natural Hazards and Earth System Science, vol. 12, no. 5, pp. 1481-1491, 2012.

[67] J. D. Ruiz Sinoga, R. Garcia Marin, J. F. Martinez Murillo, and M. A. Gabarron Galeote, "Precipitation dynamics in southern Spain: trends and cycles," International Journal of Climatology, vol. 31, no. 15, pp. 2281-2289, 2011.

[68] M. Unkašević and I. Tošić, "A statistical analysis of the daily precipitation over Serbia: trends and indices," Theoretical and Applied Climatology, vol. 106, no. 1-2, pp. 69-78, 2011.

[69] H. B. Mann, "Nonparametric tests against trend," Econometrica, vol. 13, pp. 245-259, 1945.

[70] M. G. Kendall, Rank Correlation Methods, Griffin, London, UK, 1975.

[71] E. L. Lehmann, Nonparametrics: Statistical Methods Based on Ranks, HoldenDay, San Francisco, Calif, USA, 1975.

[72] R. Sneyers, "On the statistical analysis of series of observations," Technical Note no. 143, World Meteorological Organization, Geneva, Switzerland, 1990.

[73] H. von Storch and A. Navarra, Analysis of Climate VariabilityApplications of Statistical Techniques, Springer, New York, NY, USA, 1995.

[74] J. D. Salas, J. W. Delleur, V. M. Yevjevich, and W. L. Lane, Applied Modeling of Hydrologic Time Series, Water Resources Publications, Littleton, Colo, USA, 1980.

[75] M. G. Kendall and A. Stuart, The Advanced Theory of Statistics: Design and Analysis, and Time-Series, vol. 3, Charles Griffin \& Company Limited, London, UK, 1968.

[76] M. Gocic and S. Trajkovic, "Software for estimating reference evapotranspiration using limited weather data," Computers and Electronics in Agriculture, vol. 71, no. 2, pp. 158-162, 2010.

[77] M. Gocic and S. Trajkovic, "Service-oriented approach for modeling and estimating reference evapotranspiration," Computers and Electronics in Agriculture, vol. 79, no. 2, pp. 153-158, 2011. 

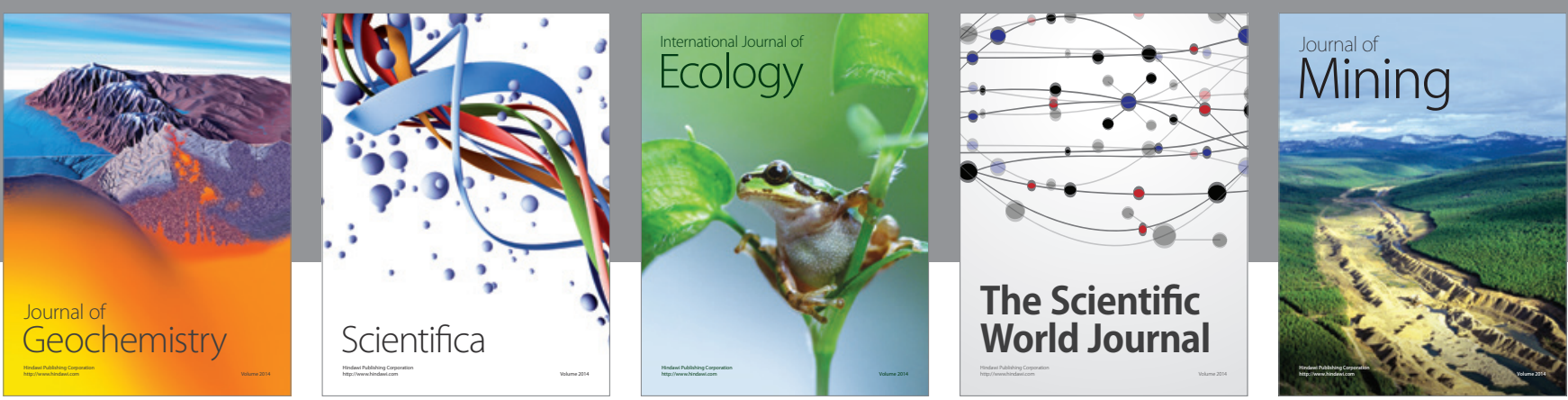

The Scientific World Journal
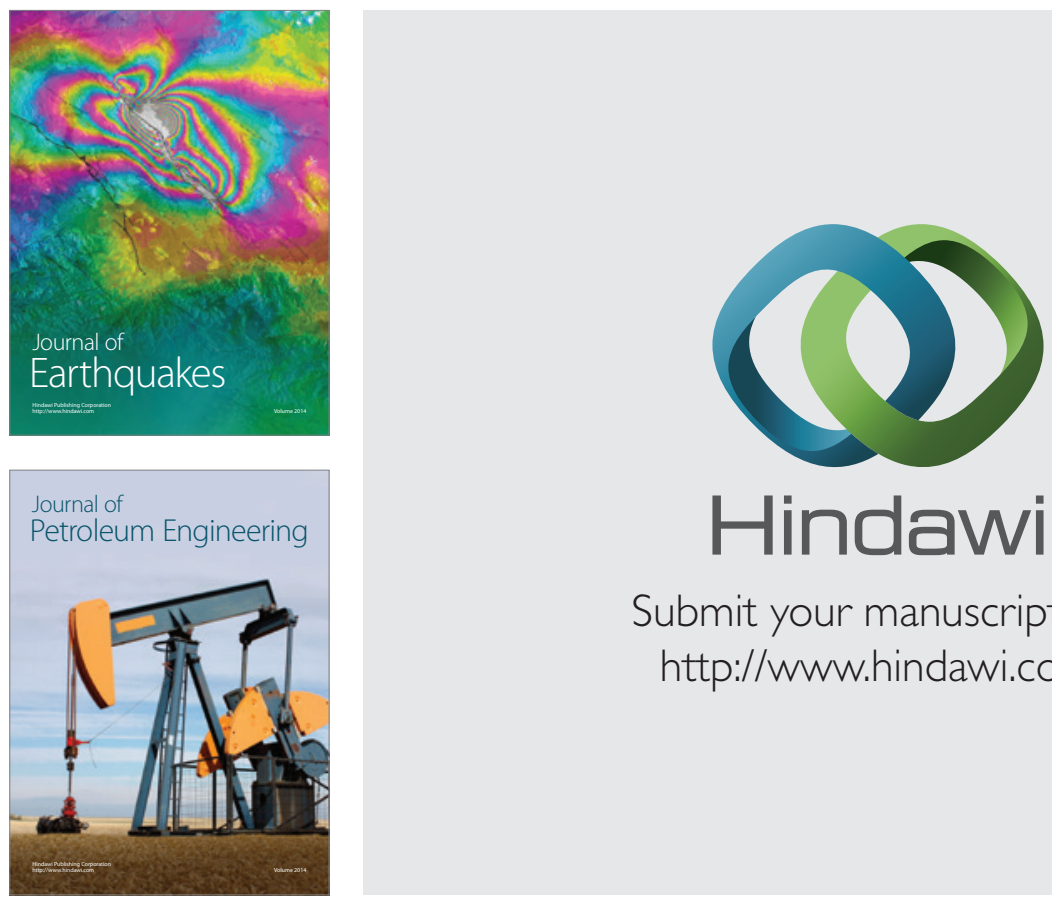

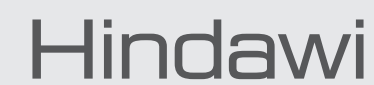

Submit your manuscripts at

http://www.hindawi.com
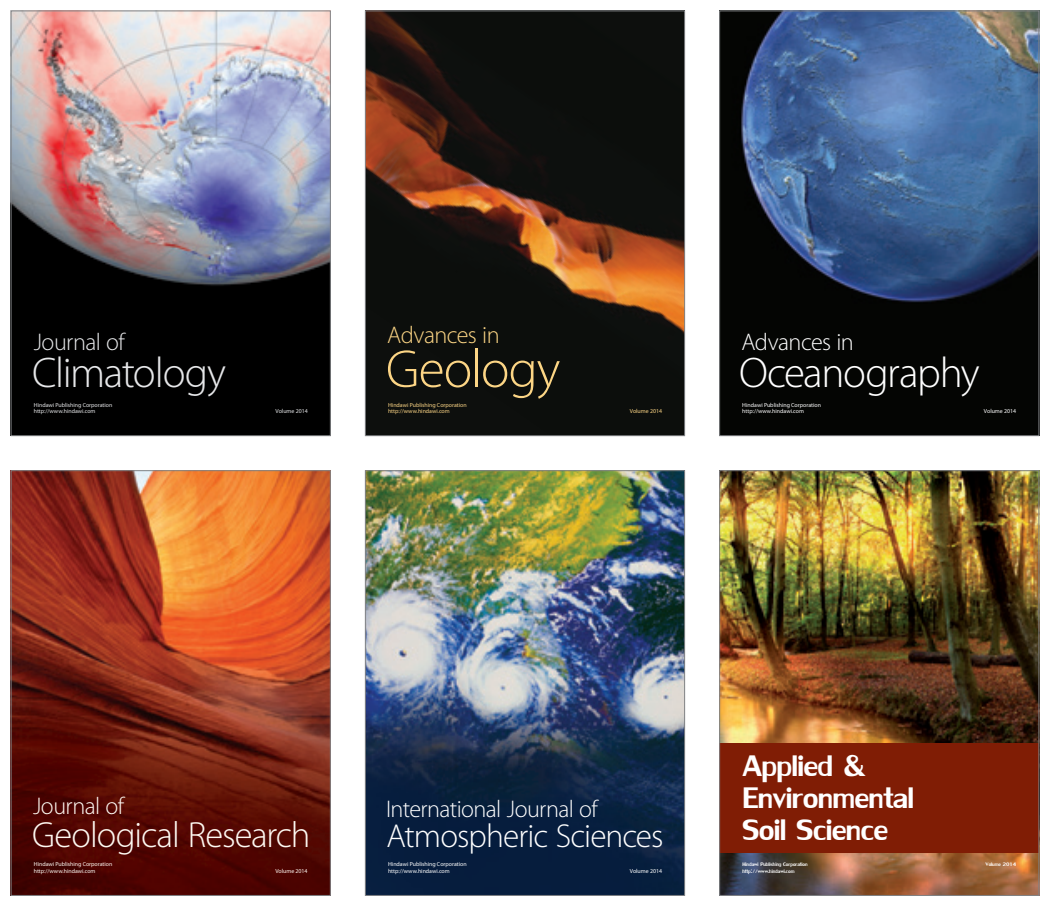
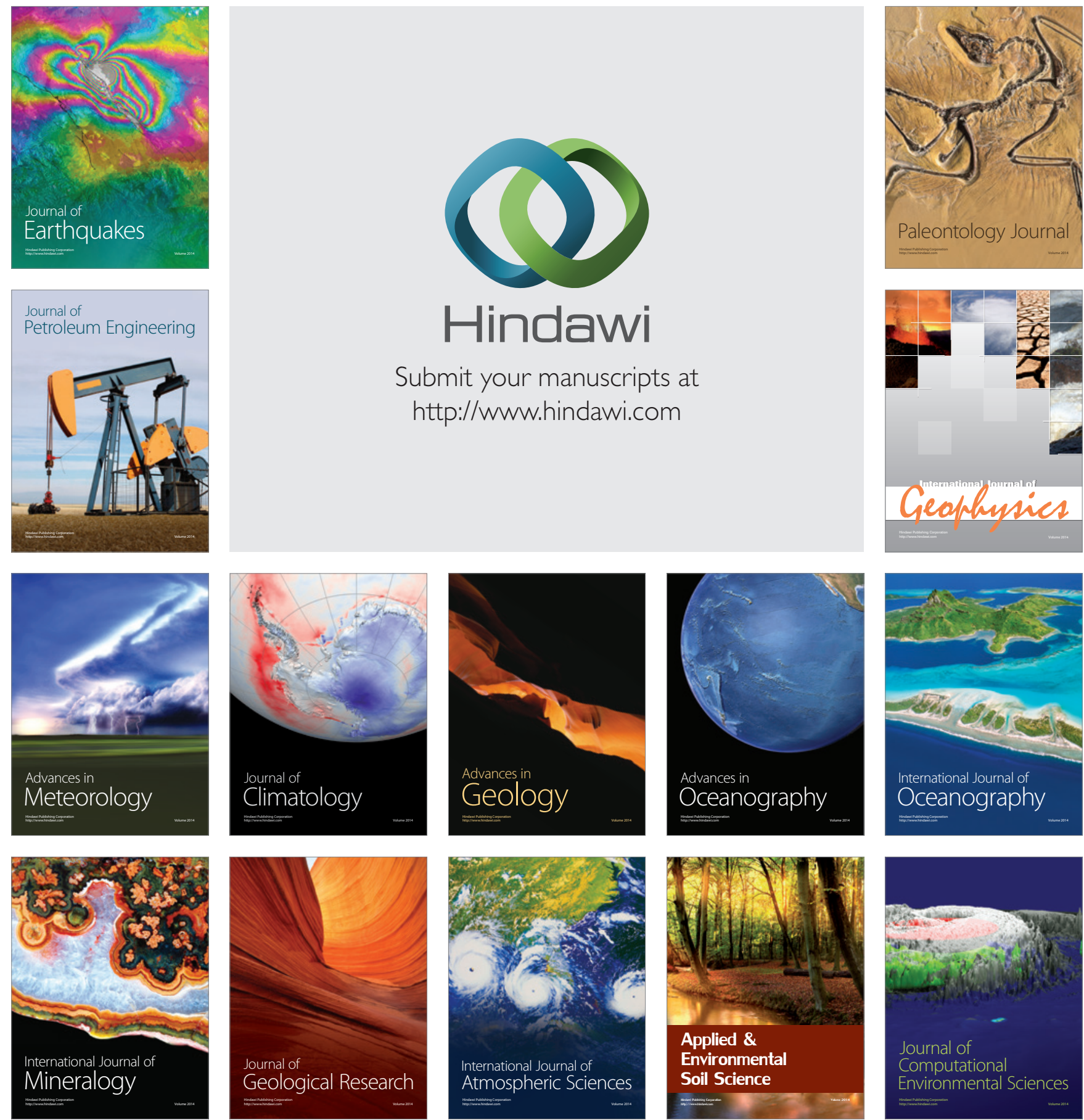